\title{
Erratum
}

\section{Heuristic combinatorial optimization by simulated Darwinian evolution: a polynomial time algorithm for the Traveling Salesman Problem}

Balamurali Krishna Ambati ${ }^{1}$, Jayakrishna Ambati ${ }^{2}$, and Mazen Moein Mokhtar ${ }^{3}$

${ }_{1}^{1}$ University at Buffalo, School of Medicine, Buffalo, NY 14214, USA

2 Department of Pharmacology, SUNY Healt Science Center, Brooklyn, NY 11203, USA

3 AT\&T Bell Labs, Naperville, IL 60565, USA

Biol. Cybern. 65, 31-35 (1991)

The following errors in the above paper are to be corrected:

Lemma 2 should read:

Lemma 2. $E_{g d}(X)=(1-p)^{-1}$ and $\sigma_{g d}^{2}(X)=p(1-p)^{-2}$

The penultimate sentence in the proof of Lemma 3 should read as: "Thus if $x(\theta ; \alpha=0)=E_{g d}+\lambda \sigma$, where $\lambda=1 / \sqrt{1-\theta}$, then $F(x(\theta)) \geqq \theta$."

The final paragraph of the conclusion should begin: "It is also appealing to consider hybrids of neural network learning algorithms with evolutionary search procedures, in view of Nature's success in this area."

Table 1 should be as follows:

Table 1. The times are normalized to the 10 -city TSP solved by evolution, because the simulations were conducted on several machines

\begin{tabular}{lllll}
\hline & \multicolumn{2}{l}{ Number of Cities } & & \\
\cline { 2 - 5 } & 10 & 20 & 50 & 100 \\
\hline $\begin{array}{l}\text { Evolution } \\
\text { Time }\end{array}$ & 1.00 & 2.84 & 8.68 & 19.68 \\
$\begin{array}{l}\text { Distance } \\
\text { Greedy }\end{array}$ & 268.3237 & 431.8781 & 620.1306 & 924.751 \\
$\begin{array}{l}\text { Time } \\
\text { Distance }\end{array}$ & 0.56 & 2.16 & 14.28 & \\
$\begin{array}{l}G A F \\
\text { Time }\end{array}$ & 506.5496 & 1075.61 & 2565.541 & 48.84 \\
Distance & 1.13 & 3.51 & 10.83 & 4899.416 \\
$\begin{array}{l}\text { Expected Min } \\
\text { Distance }\end{array}$ & 268.3237 & 431.8781 & 814.6011 & 24.11 \\
\hline
\end{tabular}

actual minimum distance 